\section{Relationship of Gender, Body Mass Index, and Axial Length with Central Retinal Thickness Using Optical Coherence Tomography}

Lo Ka Chow Memorial Ophthalmic Centre Tung Wah Eastern Hospital Causeway Bay Hong Kong

Correspondence: ACM Wong Lo Ka Chow Memorial Ophthalmic Centre

Tung Wah Eastern Hospital Causeway Bay

Hong Kong

Tel: + 85221626901

Fax: + 85228829909

E-mail: albertcmw@

sinaman.com

Received: 3 September 2003

Accepted: 6 January 2004 Published online: 16 July 2004

This study is part of the eye screening project financially supported by the Tung Wah Group Research Fund The authors have no proprietary interest in the devices used

\begin{abstract}
Background Optical coherence tomography (OCT) acquires cross-sectional retinal images with high resolution using low-coherence interferometry. Few studies have studied the effect of demographic data and ocular parameters that may affect central retinal thickness. In this study, these factors were used as parameters to analyse if any significant relationship exists with central retinal thickness.

Methods Volunteers with a best-corrected visual acuity of $6 / 12$ or better and no evidence of ocular abnormalities or interventions were recruited from October 2001 to March 2003. Body mass index (BMI), autorefraction, and keratometry recordings were measured, followed by applanation tonometry and Ascan ultrasonography. The central retinal thickness of the right eye was analysed using a scan length of $3 \mathrm{~cm}$. Another 25 eyes were selected for interobserver reproducibility. Results In all, 117 normal subjects (60 male and 57 female subjects) were recruited. The mean thickness of the central retina with a diameter of $1 \mathrm{~mm}$ was $203 \pm 23 \mu \mathrm{m}$ for male and $189 \pm 20 \mu \mathrm{m}$ for female subjects. Age, intraocular pressure, and keratometric readings were not significantly correlated with central retinal thickness. Using multiple regression, gender, $\mathrm{BMI}$, axial length, and signal-to-noise ratio $(P<0.05)$ were significantly associated with the central retinal thickness. The intraclass correlation coefficient was 0.98 for interobserver reproducibility. Conclusion OCT has a high interobserver reproducibility. The male gender, larger BMI,
\end{abstract}

ACM Wong, CWN Chan and SP Hui

and longer axial length are associated with a significantly thicker central retina and these parameters should be considered for assessing retinal thickening and baseline comparisons in future studies.

Eye (2005) 19, 292-297. doi:10.1038/sj.eye.6701466 Published online 16 July 2004

Keywords: optical coherence tomography; axial length; gender; body mass index; Chinese

\section{Introduction}

Optical coherence tomography (OCT) is a diagnostic imaging device that can acquire tomographic imaging of the retina with high resolution using low-coherence near infrared interferometry. ${ }^{1}$ It can be used to assess retinal thickness and pathologies quantitatively and qualitatively in patients with diabetic macular oedema, ${ }^{2-4}$ macular hole, ${ }^{5}$ retinoschisis, ${ }^{6}$ and pseudophakic cystoid macular oedema. ${ }^{7-9}$ Previous studies have shown that OCT has high reproducibility and repeatability. ${ }^{10-12}$ Some studies found that central retinal thickness in males were significantly higher than in female subjects. ${ }^{13}$ However, few studies have studied the effect of other demographic data and ocular parameters that can possibly affect the central retinal thickness.

The aim of this study is to assess the correlations of age, gender, body mass index (BMI), and ocular dimensions including refractive error, keratometric reading, intraocular pressure (IOP) and axial length in normal subjects with central retinal thickness. These parameters may need to be 
taken into account when comparing the control and treatment groups in future studies.

\section{Methods}

\section{Equipment}

OCT acquires high-axial resolution (10-14 $\mu \mathrm{m})$ crosssectional imaging of the retina that directly measures optical reflectivity in the $z$-plane (depth of the retina). It detects relative changes in reflection at optical interfaces by the method of low-coherence interferometry. The outermost (red-white) band corresponds to the retinal pigment epithelium-choriocapillaris complex, while the innermost band corresponds to the surface-related signal. The thickness between them corresponds to the retinal thickness. ${ }^{14-16}$

The retinal images were acquired by either one of two experienced operators using the Carl Zeiss Humphrey OCT II (Humphrey instruments, Hacienda Drive, Dublinm, CA, USA, software version A6.1). The light source was a superluminescent diode with a wavelength of $850 \mathrm{~nm}$. The power could reach a maximum of $750 \mu \mathrm{W}$ and the image acquisition time was approximately $2.5 \mathrm{~s}$ for each scan which consists of 100 longitudinal A-scans regardless of the scan-length. The software assumes a refractive index of 1.38 for retinal tissue as provided by the manufacturer of this system.

\section{Subjects}

The study was conducted in accordance with the Declaration of Helsinki recommendations. The subjects were recruited by distributing pamphlets in primary and secondary schools, public health talks, and within the hospital. The pamphlets contained a questionnaire to exclude subjects with a history of diabetes, retinal pathologies, ocular interventions, refractive error of spherical power of more than -6.00 or +6.00 dioptres, as well as cylindrical power of more than -2.50 dioptres. Those selected were invited to our hospital for screening and examination from October 2001 to March 2003. The inclusion criteria of normal subjects included a bestcorrected visual acuity of $6 / 12$ or better, cup-disc ratio of 0.5 or less, a mean of three measurements of IOP of $21 \mathrm{mmHg}$ or less, and no evidence of ocular abnormalities or interventions.

Before any examination, the procedure was explained to each volunteer and the consent form was signed. Height and weight measurements were measured first. Noncontact measurements of autorefraction and keratometry recordings were performed using autokerato-refractometer (Topcon KR-8100PA), followed by applanation tonometry (Goldmann) and axial length measurement using Ocuscan (Alcon lab, TX, USA). Both pupils were then dilated with Mydrin-P $(0.5 \%$ tropicamide and $0.5 \%$ phenylephrine) before retinal scanning. In all, 117 subjects, aged 13 to 81 years, fulfilled the above criteria. Another 25 volunteers were chosen to receive duplicate measurement so that the interobserver reproducibility could be assessed.

\section{Scanning}

Each subject was asked to gaze at an internal fixation light within the machine and six scans were taken with each scan centred on the fovea. The scan length on the OCT system was set to $3 \mathrm{~mm}$ using the default axial length of $24.46 \mathrm{~mm}$ and refractive error of 0 . This is the normal practice of OCT measurement. The six scans were performed in a radial spoke pattern at $0,30,60,90,120$, and $150^{\circ}$, using a power of $750 \mu \mathrm{W}$. Each of the six tomograms contained 100 equally spaced axial profiles of optical reflectivity. Thus, retinal thickness was measured at a total of 600 points along these six intersecting lines. A retinal map that divided the scanned area into nine zones (A1-A9) was produced by the OCT software (Figure 1). In our study, the measurements of central $1 \mathrm{~mm}$ retinal thickness (A1) of the right eyes were used for analysis. The standard deviations of foveal measurements of the six scans on the eyes in this study were all within $15 \mu \mathrm{m}$. The signal-to-noise ratio $(S / N)$ of each measurement is to show the quality of the scans and this was included in our analysis.

\section{Statistical methods}

The measurements of 25 eyes were repeated by another operator immediately after the examination by the first operator. The difference between the two operators was assessed using the Wilcoxon signed rank test (5\% level of significance).

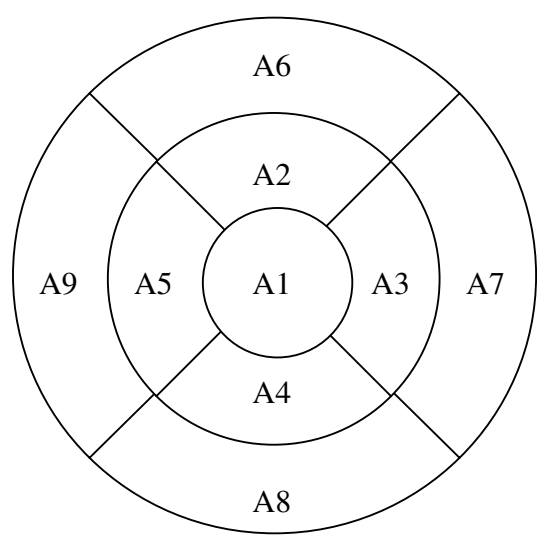

Figure 1 Retinal map of the right eye. 
The data of right eyes of the 117 subjects were analysed using SPSS 10.0. Independent two-sample $t$-test was used to test the difference between the two genders, and Pearson's correlation and linear regression tests were used to assess the relationship of central $1 \mathrm{~mm}$ retinal thickness with spherical equivalence, BMI, axial length, and $S / N$ ratio. The significant variables found in the univariate methods could be analysed using multiple regression.

\section{Results}

\section{Interobserver reproducibility}

Using Wilcoxon analysis on the duplicated measurements of 25 volunteers, no statistical difference was found between the two experienced operators. The intraclass correlation coefficient (ICC) was 0.98 (95\% CI 0.95-0.99).

\section{Central $1 \mathrm{~mm}$ retinal thickness}

A total of 117 normal subjects (60 male and 57 female subjects), with a mean age of $40.6 \pm 16.4$ years and a mean BMI of $22.7 \pm 3.15 \mathrm{~kg} / \mathrm{m}^{2}$, had a mean spherical equivalence of $-1.41 \pm 2.63$ dioptres and a mean keratometric reading of $43.42 \pm 1.35$ dioptres. The mean axial length and IOP were $24.3 \pm 1.3 \mathrm{~mm}$ and $13.5 \pm 3.12 \mathrm{mmHg}$, respectively. The findings are summarized in Table 1.

The central retinal thickness of the 117 subjects was distributed normally as assessed by the q-q plot. The mean thickness of the central $1 \mathrm{~mm}$ retina of the right eyes was $203 \pm 23 \mu \mathrm{m}$ for male and $189 \pm 20$ microns for female subjects.

\section{Univariate methods}

Using independent two-sample $t$-test, the mean central retinal thickness in males was significantly higher than in

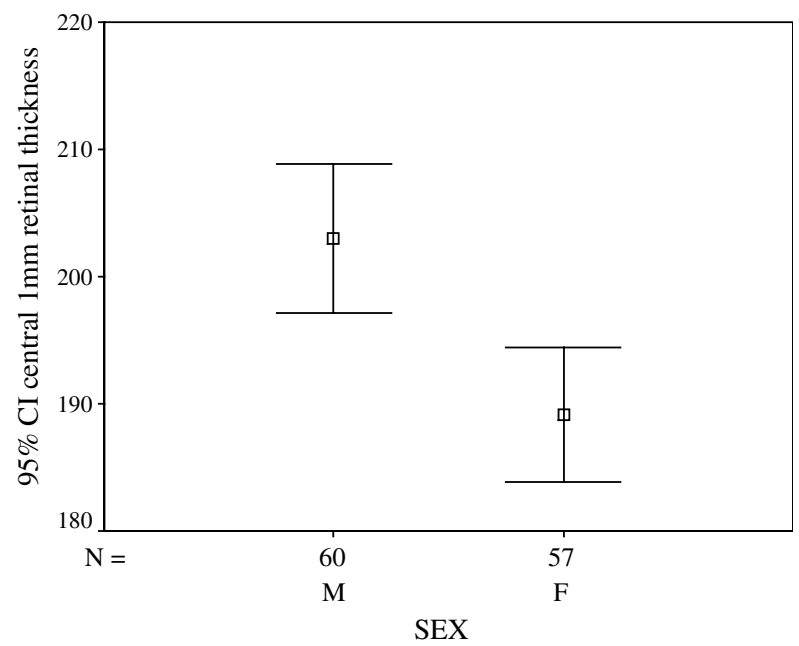

Figure 2 Error bar of central retinal thickness in male and female subjects.

female subjects. ( $P=0.001)$ (Figure 2). Using Pearson's correlation tests, significant correlation was found between the mean central $1 \mathrm{~mm}$ retinal thickness and spherical equivalence $(r=-0.216, P<0.05)$, BMI $(r=0.222, P<0.05)$, axial length $(r=0.308, P<0.01)$, and $S / N$ ratio $(r=-0.276, P<0.01)$. There was no significant correlation with age $(P=0.850)$, IOP $(P=0.547)$, or average keratometric readings $(P=0.068)$.

When compared with retinal readings in the tomographic measurement, the central $1 \mathrm{~mm}$ retinal thickness was found to be correlated with the central $2.22 \mathrm{~mm}$ thickness (by averaging the thickness of A1-A5) (mean of central $2.22 \mathrm{~mm}$ thickness $=247 \pm 18 \mu \mathrm{m}$, $r=0.888, P<0.01$ ), the foveal thickness (mean $=171 \pm 22 \mu \mathrm{m}, r=0.881, P<0.01$ ), the total volume (mean $=2.44 \pm 0.15 \mathrm{~mm}^{3}, r=0.706, P<0.01$ ), and the $S / N$ ratio $($ mean $=51.96 \pm 3.5, r=-0.276, P<0.01$ )

Similarly, Pearson's correlation tests were performed on foveal thickness, which was significantly correlated with spherical equivalence ( $r=-0.204, P<0.05)$, BMI $(r=0.224, P<0.05)$, axial length $(r=0.260, P<0.01)$, and

Table 1 Summary of different parameters in the present study

\begin{tabular}{lll}
\hline Measure mean $\pm S D(\min -\max )$ & Male subjects $(\mathrm{n}=60)$ & Female subjects $(\mathrm{n}=57)$ \\
\hline Age & $42.3 \pm 16.4(13-81)$ & $38.6 \pm 16.1(16-79)$ \\
IOP $(\mathrm{mmHg})$ & $13.5 \pm 3.2(5.67-19.67)$ & $13.5 \pm 3.1(6.67-20.33)$ \\
BMI $\left(\mathrm{kg} / \mathrm{m}^{2}\right)$ & $23.4 \pm 2.7(17.24-28.15)$ & $22.1 \pm 3.4(16.34-29.32)$ \\
Spherical equivalence (dioptres) & $-1.57 \pm 2.5(-5.88 \pm 3.50)$ & $-1.92 \pm 2.68(-5.88 \pm 5.12)$ \\
Axial length $(\mathrm{mm})$ & $24.6 \pm 1.31(20.52-27.37)$ & $24.0 \pm 1.21(21.32-26.82)$ \\
$S / N$ ratio $(\mathrm{dB})$ & $52 \pm 3(45-61)$ & $52 \pm 4(45-61)$ \\
Foveal thickness $(\mu \mathrm{m})$ & $174 \pm 21(133-220)$ & $168 \pm 23(113-225)$ \\
Central $1 \mathrm{~mm}$ thickness $(\mu \mathrm{m})$ & $203 \pm 23(163-259)$ & $189 \pm 20(138-226)$ \\
Total volume $\left(\mathrm{mm}^{3}\right)$ & $2.49 \pm 0.15(2.20-2.84)$ & $2.39 \pm 0.12(2.11-2.61)$ \\
\hline
\end{tabular}

IOP Intra-ocular pressure; BMI body mass index; $S / N$ signal-to-noise ratio. 
$S / N$ ratio $(r=-0.328, P<0.01)$. There was no significant correlation with age $(P=0.270)$, IOP $(P=0.227)$, or average keratometric readings $(P=0.183)$. Axial length was significantly correlated with spherical equivalent ( $r=-0.741, P<0.001)$ but not correlated with BMI $(P=0.171)$. Age was not correlated with $S / N$ ratio $(P=0.561)$.

When linear regression was performed with each independent variable, the relationships of central $1 \mathrm{~mm}$ retinal thickness with axial length, $\mathrm{BMI}$, and $S / N$ ratio

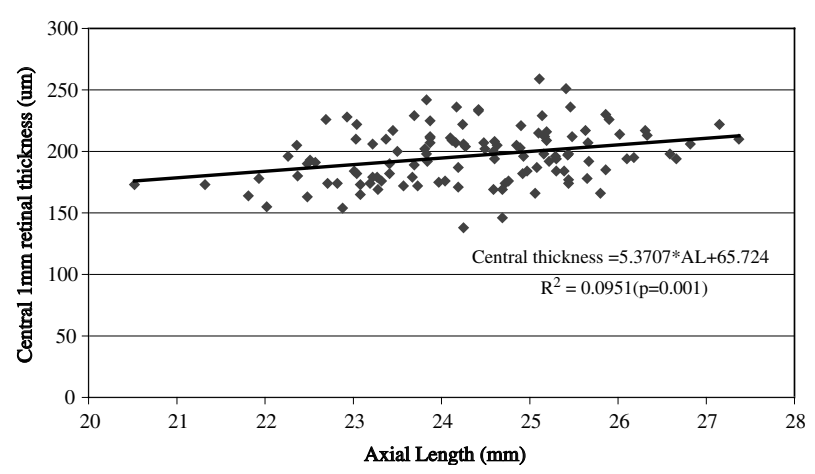

Figure 3 Scatter plot and the regression line of the central retinal thickness against axial length.

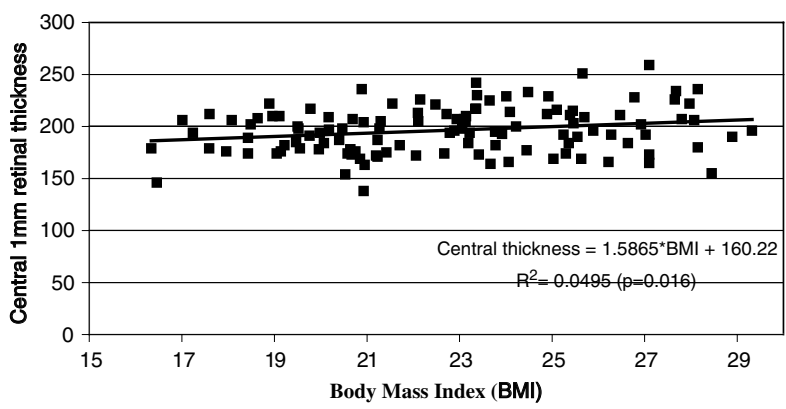

Figure 4 Scatter plot and the regression line of the central retinal thickness against $\mathrm{BMI}$.

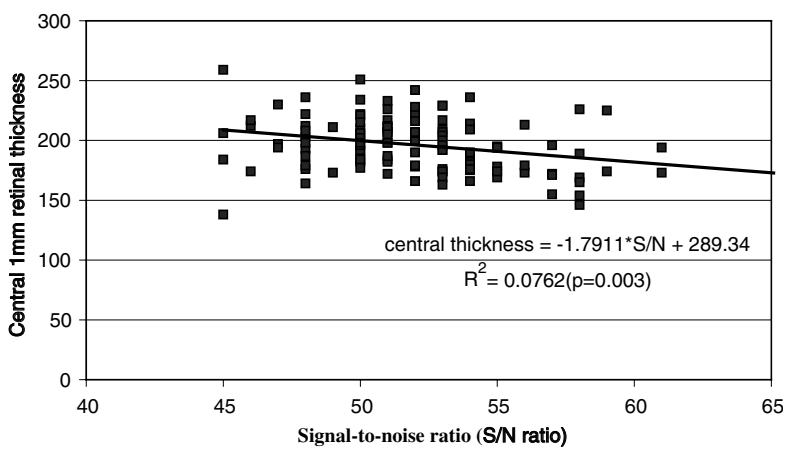

Figure 5 Scatter plot and the regression line of the central retinal thickness against $S / N$ ratio. are shown by Figures 3-5. In Figure 3, the scatter plot shows a mild positive correlation between central $1 \mathrm{~mm}$ retinal thickness and the axial length with the regression model: central thickness $=5.3707 \mathrm{AL}+65.7\left(r^{2}=0.0951\right.$, $P=0.001$ ). In Figure 4 , the positive correlation between the central $1 \mathrm{~mm}$ retinal thickness and BMI could be expressed using the following equation: central thickness $=1.5865 \mathrm{BMI}+160.22\left(r^{2}=0.0495, P=0.016\right)$. In contrast to the previous figures, Figure 5 shows a negative correlation between central retinal thickness and $S / N$ ratio: central thickness $=-1.7911 S / N+289.34$ $\left(r^{2}=0.0762, P=0.003\right)$.

\section{Multivariable methods}

Using multiple regression with a stepwise procedure, all the significant parameters were adjusted. Parameters including BMI, gender, axial length, and $S / N$ ratio were still found to be significantly associated with central retinal thickness. In our study, their relationships can be described in the equation below:

Central $1 \mathrm{~mm}$ retinal thickness $=126.847+9.029$ Gender +4.455 axial length $+1.4 \mathrm{BMI}-1.45 S / N$ ratio $\left(r^{2}=0.247, P=0.024\right)$

\section{Discussion}

OCT is a relatively new device that is useful in assessing the retina quantitatively and qualitatively. Interobserver reproducibility in OCT measurement of retinal thickness has been studied previously. Massin et al ${ }^{12}$ showed that the ICCs was 0.99. Baumann et $a l^{7}$ and Neubauer et $a l^{18}$ also showed high reproducibility in terms of low coefficients of variation. The ICC of interobserver reproducibility in our study was 0.98 , which is comparable with previous studies. ${ }^{12,17,18}$

Our finding that males have a thicker central retina is in agreement with the study of Massin et al. ${ }^{13}$ The 95\% confidence interval was $184-194 \mu \mathrm{m}$ in women and 197-209 $\mu \mathrm{m}$ in men. Our study shows that there is no relationship of central retinal thickness with age, which is consistent with the study of Massin et al but not with those of Kanai et $a l^{19}$ and Alamouti and Funk. ${ }^{20}$ However, Alamouti was using the scan aligned vertically and placed at the temporal edge of the optic disc, which is a different measurement site from ours. Kanai also used a different reference point on the retina. This suggests that the relationship of retinal thickness with age may depend on the measurement site of the retina.

Quantitative analysis of central retinal thickness with topographic mapping of the retina has been used to assess various retinal pathologies in previous studies. 
Sanchez-Tocino et $a l^{2}$ suggested that a foveal thickness of over $180 \mu \mathrm{m}$ may be useful for the early detection of the macular thickening in a diabetic patient. However, such a cutoff value may not be universally applied to all ethnic groups as the mean foveal thickness was $171 \pm 22 \mu \mathrm{m}$ in our healthy subjects, which may be due to ethnic differences. We also found that $S / N$ ratio taken in the machine, axial length, and BMI in each individual may affect the measurement of the central retinal thickness. As obesity is a common feature in diabetic patients, ${ }^{21,22}$ BMI should be considered when comparing diabetic and nondiabetic groups in future studies.

While Kanai et $a l^{19}$ and Gobel et $a l^{23}$ found that axial length was not correlated with the retinal thickness, we found that there was a significant correlation between axial length and retinal thickness $(r=0.308, P<0.01)$. Possible reasons to explain the difference between our findings and other studies could be due to the small sample size or ethnic differences in previous studies. In our study, longer eyes were found to have a thicker central retina. Whether the retinal thickness is apparently thicker in longer axial length due to longer travel distance inside the eye would be difficult to prove in vivo as histopathological verification was difficult to obtain. However, in our study, we found that foveal thickness is also related to the axial length. This may prove that the change of retinal thickness is real rather than apparent. Also, the optical coherence tomographic imaging of tissues is dependent on their optical properties and is based on low-coherence interferometry that measures distances to objects by measuring light reflected from them. The detector, which is sensitive to the electric field, measures the intensity of the output optical beam. The intensity is proportional to the square of the electromagnetic field. ${ }^{24}$ As Muscat et $a l^{10}$ showed that the measurements of gap thickness were still accurate, precise, and repeatable under different media, we believe that there is a real central retinal thickening in eyes with longer axial length.

As for the limitations in our study, our regression model has the coefficient of determination $\left(r^{2}\right)$ of 0.247 when using axial length, BMI, gender, and $S / N$ ratio. So, our study has only evaluated some of the parameters that may affect retinal thickness and there could be other parameters affecting retinal thickness.

In conclusion, our study shows that the measurement of retinal thickness by OCT has a high interobserver reproducibility and may be affected by parameters such as gender, BMI, and axial length. Such parameters should be considered in assessing retinal thickening and baseline comparison of these parameters should be considered in future studies.

\section{Acknowledgements}

We thank Yee Mee Wong, Eddie Chi Fai Kwok and Ann Wai Yin Yip for their skill and support; and Daniel Yee Tak Fong for statistical advice.

\section{References}

1 Huang D, Swanson CA, Lin CP, Schuman JS, Stinson WG, Chang W et al. Optical coherence tomography. Science 1991; 254(5035): 1178-1181.

2 Sanchez-Tocino H, Alvarez-Vidal A, Maldonado MJ, Moreno-Montanes J, Garcia-Layana A. Retinal thickness study with optical coherence tomography in patients with diabetes. Invest Ophthalmol Vis Sci 2002; 43(5): 1588-1594.

3 Strom C, Sander B, Larsen N, Larsen M, Lund-Andersen H. Diabetic macular edema assessed with optical coherence tomography and stereo fundus photography. Invest Ophthalmol Vis Sci 2002; 43(1): 241-245.

4 Yang CS, Cheng CY, Lee FL, Hsu WM, Liu JH. Quantitative assessment of retinal thickness in diabetic patients with and without clinically significant macular edema using optical coherence tomography. Acta Ophthalmol Scand 2001; 79(3): 266-270.

5 Pal E, Givort G, Laroche A, Barale PO, Limon S, Ullern M. Macular imaging with optical coherence tomography. $\mathrm{Fr}$ Ophtalmol 1998; 21(7): 484-494 (in French).

6 Benhamou N, Massin P, Haouchine B, Erginay A, Gaudric A. Macular retinoschisis in highly myopic eyes. Am J Ophthalmol 2002; 133(6): 794-800.

7 Grewing R, Becker H. Retinal thickness immediately after cataract surgery measured by optical coherence tomography. Ophthalmic Surg Lasers 2000; 31(3): 215-217.

8 Sourdille P, Santiago PY. Optical coherence tomography of macular thickness after cataract surgery. J Cataract Refract Surg 1999; 25(2): 256-261.

9 Cheng B, Liu Y, Liu X, Ge J, Ling Y, Zheng X. Macular image changes of optical coherence tomography after phacoemulsification. Chung Hua Yen K'o Tsa Chih 2002; 38(5): 265-267 (in Chinese).

10 Muscat S, McKay N, Parks S, Kemp E, Keating D. Repeatability and reproducibility of corneal thickness measurements by optical coherence tomography. Invest Ophthalmol Vis Sci 2002; 43(6): 1791-1795.

11 Koozekanani D, Roberts C, Katz SE, Herderick EE. Intersession repeatability of macular thickness measurements with the Humphrey 2000 OCT. Invest Ophthalmol Vis Sci 2000; 41(6): 1486-1491.

12 Massin P, Vicaut E, Haouchine B, Erginay A, Paques M, Gaudric A. Reproducibility of retinal mapping using optical coherence tomography. Arch Ophthalmol 2001; 119(8): 1135-1142.

13 Massin P, Erginay A, Haouchine B, Mehidi AB, Paques M, Gaudric A. Retinal thickness in healthy and diabetic subjects measured using optical coherence tomography mapping software. Eur J Ophthalmol 2002; 12(2): 102-108.

14 Hee MR, Izatt JA, Swanson EA, Huang D, Schuman JS, Lin CP et al. Optical coherence tomography of the human retina. Arch Ophthalmol 1995; 113(3): 325-332.

15 Chauhan DS, Marshall J. The interpretation of optical coherence tomography images of the retina. Invest Ophthalmol Vis Sci 1999; 40(10): 2332-2342. 
16 Toth CA, Narayan DG, Boppart SA, Hee MR, Fujimoto JG, Birngruber $\mathrm{R}$ et al. A comparison of retinal morphology viewed by optical coherence tomography and by light microscopy. Arch. Ophthalmol 1997; 115(11): 1425-1428.

17 Baumann M, Gentile RC, Liebmann JM, Ritch R. Reproducibility of retinal thickness measurements in normal eyes using optical coherence tomography. Ophthalmic Surg Lasers 1998; 29(4): 280-285.

18 Neubauer AS, Priglinger S, Ullrich S, Bechmann M, Thiel MJ, Ulbig MW et al. Comparison of foveal thickness measured with the retinal thickness analyzer and optical coherence tomography. Retina 2001; 21(6): 596-601.

19 Kanai K, Abe T, Murayama K, Yoneya S. Retinal thickness and changes with age. Nippon Ganka Gakkai Zasshi 2002; 106(3): 162-165 (in Japanese).
20 Alamouti B, Funk J. Retinal thickness decreases with age: OCT study. Br J Ophthalmol 2003; 87(7): 899-901.

21 Feher MD, Cox A, Foxton J, Lant AF. Fat arms, obesity and choice of blood pressure cuff size in diabetic patients. $\mathrm{Br} J$ Clin Pract 1995; 49(6): 286-287.

22 Bani IA, Anokute C. A pilot epidemiologic study of diabetes mellitus in the Sudan. J R Soc Health 1994; 114(4): 178-781.

23 Gobel W, Hartmann F, Haigis W. Determination of retinal thickness in relation to the age and axial length using optical coherence tomography. Ophthalmologe 2001; 98(2): 157-162 (in German).

24 Puliafito CA, Hee MR, Schuman JS, Fujimoto JG. Optical Coherence Tomography of Ocular Diseases. Slack Inc.: Thorofare, NJ,, 1996 pp 369-374. 